\title{
As crenças ambientais de trabalhadores provenientes de empresa certificada por SGA podem predizer comportamentos pró-ambientais fora da empresa?
}

\author{
Camila Bolzan de Campos \\ Faculdade de Tecnologia Tecbrasil \\ Enric Pol \\ Universidade de Barcelona
}

\begin{abstract}
Resumo
A implantação e utilização de Sistemas de Gestão Ambiental (SGA) requer das empresas uma nova postura, uma mudança ambiental, sobretudo, na rotina de seus trabalhadores, em suas crenças ambientais e em seus comportamentos pró-ambientais fora da empresa. O presente artigo visa analisar as diferenças nas crenças ambientais, considerando a estrutura dicotômica antropocentrismo x ecocentrismo, em três grupos de trabalhadores brasileiros: provenientes de empresas certificadas por SGA $(n=232)$, não certificadas $(n=153)$ e não certificadas com política ambiental $(n=169)$. Ao mesmo tempo, se verificou o potencial preditor das crenças ambientais sobre os comportamentos pró-ambientais. Os resultados apontam que os trabalhadores que são de empresas não certificadas e não certificadas com política ambiental apresentam pontuações mais elevadas de crenças ambientais de tipo antropocêntricas. Além disto, se constatou que ser de uma empresa certificada e possuir crenças ecocêntricas são variáveis que possuem efeito explicativo sobre alguns fatores do comportamento pró-ambiental.
\end{abstract}

Palavras-chave: sistemas de gestão ambiental; crenças ambientais; comportamentos pró-ambientais; trabalhadores.

\begin{abstract}
Can the environmental beliefs of workers from environmental certified companies predict their environmental behavior outside the organization? The implementation and utilization of Environmental Management Systems (EMS) requires new approach for the companies, and an environmental change, even in their workers routine, environmental beliefs and in their environmental behaviors outside the company. This paper aims to analyze the differences between the environmental beliefs, considering the dichotomy anthropocentrism $\mathrm{x}$ ecocentrism structure in three groups of Brazilian workers: from companies certified by an EMS $(n=232)$, non certified $(n=153)$ and non certified with environmental policy $(n=169)$. At the same time, we verified the potential of prediction of the environmental beliefs over the environmental behaviors. The results points out that the workers from companies non certified and non certified with environmental policy mostly presented high level of anthropocentric beliefs. Furthermore, being an EMS worker and presenting ecocentric beliefs can explain some of environmental behavior factor.
\end{abstract}

Keywords: environmental management systems; environmental beliefs; environmental behavior; workers.

A preocupação com a deterioração do meio ambiente como resultado de ações humanas é foco de discussão de partidos políticos e órgãos internacionais desde a década de 1970 (Intergovernmental Panel on Climate Change, 2007). Surgiram daí alguns avanços que culminaram em acordos ambientais multilaterais, como, por exemplo, o Protocolo de Kyoto. Essa "nova era" ambiental trouxe consigo a ênfase em normativas, legislações e exigências ambientais específicas propondo ações urgentes para minimizar a degradação ambiental e garantir uma melhoria na qualidade de vida, que acabaram recaindo ao cidadão, às empresas e às administrações públicas.
Do ponto de vista individual, o cidadão pode minimizar o impacto de suas atividades rotineiras sobre o meio ambiente realizando comportamentos pró-ambientais como separar os resíduos domésticos, economizar energia ou água ou comprar produtos orgânicos. O comportamento pró-ambiental para Suárez (2000) se refere a um conjunto de atividades humanas cujo objetivo é minimizar os efeitos negativos sobre o meio ambiente. É válido acrescentar aqui o sentido de agir a favor do meio ambiente, também citado como ecológico ou pró-ecológico por Pato e Tamayo (2006), que ressaltam a presença de intenção ou não de exercer tais condutas, além de seu impacto e sua 
integração no cotidiano.

Por outro lado, os efeitos gerados pela intervenção das grandes empresas no meio ambiente são os mais preocupantes. Seja por pressões de mercado, legislativas ou de concorrência, as organizações tiveram que revisar seu modo de produção buscando atuar com mais responsabilidade ambiental. Para reduzir seu impacto ambiental, uma tendência foi gerar mudanças internas, em políticas relacionadas ao meio ambiente e, consequentemente, no comportamento de seus trabalhadores, por meio da implantação dos Sistemas de Gestão Ambiental (Tinsley \& Pillai, 2006).

Como apontam Tinsley e Pillai (2006), o surgimento dos Sistemas de Gestão Ambiental (SGA) ocorreu na década de 1980, num momento em que muitas companhias americanas começaram a realizar esforços para cumprir as crescentes exigências legislativas do país. Em paralelo a isso, algumas empresas europeias que cultivavam atitudes ambientais proativas, estavam desenvolvendo seus próprios sistemas orientados a oportunidades de negócio futuras. Na década seguinte, em 1996, detectando a necessidade de estabelecer um SGA de âmbito internacional, a International Organization for Standarization (ISO) lançou a série ISO 14000. Hillary (2000) aponta que entre suas vantagens estão a satisfação de demandas do mercado internacional, assim como dos grupos de interesse.

Para que as certificações sejam reconhecidas, existem órgãos que controlam esses processos. Além da certificação de âmbito internacional da ISO, ainda se pode citar a europeia Eco-Management and Auditing Scheme (EMAS), que é controlada pelos órgãos governamentais de meio ambiente, que se responsabilizam pela auditoria e certificação. No Brasil, o Instituto Nacional de Metrologia, Normalização e Qualidade Industrial (Inmetro) é o responsável por controlar e credenciar as agências certificadoras, ou seja, aquelas que auditam e conferem a credencial ambiental das empresas que buscam o certificado ambiental ISO 14000. Em 2008, este instituto indicou 827 unidades de negócio existentes no país que possuíam a certificação ISO 14000 (Inmetro, 2008). Segundo Alberton e Costa Jr. (2007), para países em desenvolvimento optar por certificação ambiental é altamente custoso e pouco rentável em curto prazo, o que valoriza o esforço e as iniciativas destas empresas. Da mesma forma, reitera-se a responsabilidade social e ambiental das organizações que apoiam sua gestão com SGA, uma vez que seus efeitos estão presentes no cotidiano de seus trabalhadores e dos comportamentos destes.

A implantação e a manutenção do SGA coincidem com a adoção de uma série de processos organizacionais para o seu êxito, nos quais a participação dos trabalhadores é decisiva. Junto a isso, tal processo supõe uma mudança organizacional, já que há inserção do valor ambiental antes não considerado em suas políticas. Segundo Fussler e James (1998), mesmo que estes sistemas não estimulem mudanças radicais, é esperável que estas ocorram de maneira sistemática, gradual e efetiva.

Por meio das novas práticas ambientais exigidas pelo SGA, incorporadas pelo trabalhador no ambiente de trabalho, o presente artigo pretende verificar a possível transmissão destes comportamentos para o âmbito privado. É valido ressaltar que ainda há pouca divulgação de resultados de pesquisas que, analisando amostras de trabalhadores, estabeleça relações entre comportamentos pró-ambientais, crenças ambientais e presença dos SGA. Pode-se mencionar o estudo de García-Mira, Santos, Gómez-Duran, Romay, e Fernández (1998), em que se trabalhou com uma amostra de trabalhadores de empresa petrolífera, porém com enfoque na relação entre a educação ambiental e a percepção a respeito dos problemas ambientais.

Em linhas gerais, considera-se que a presença de SGA promove mudança organizacional e, por sua vez, individual, podendo incidir no sistema de crenças ambientais dos trabalhadores. Desta forma, o presente estudo buscou, por um lado, verificar se existiam diferenças nas crenças ambientais de trabalhadores provenientes de empresas certificadas, não certificadas e não certificadas com política ambiental. Por outro lado, também foi discutido o poder preditivo das crenças ambientais sobre os comportamentos pró-ambientais dos trabalhadores fora da empresa.

\section{Crenças ambientais: possíveis precursoras dos com- portamentos pró-ambientais?}

A literatura reitera que as crenças ambientais são elementos componentes em um sistema de crenças e/ou visão de mundo. Neste sistema de crenças, os seres humanos são parte integrante do ecossistema (Corral-Verdugo, 2001; Stern, Dietz, Kalof, \& Guagnano, 1995). Este enfoque está em sintonia com o Novo Paradigma Ambiental, modelo proposto por Van Liere e Dunlap $(1978,1981)$, revisado e renomeado posteriormente como Novo Paradigma Ecológico (Dunlap, 2008; Dunlap, Van Liere, Mertig, \& Jones, 2000).

Durante as últimas três décadas, a pesquisa em Psicologia Ambiental vem demonstrando preocupação em determinar variáveis que antecedem ou predizem os comportamentos próambientais (Corral-Verdugo, 2001; Corral-Verdugo \& Pinheiro, 1999). Entre as variáveis capazes de explicar os comportamentos pró-ambientais, pode-se citar: os valores individuais (Amérigo \& González, 2001; Grob, 1995; Stern, Dietz, \& Kalof, 1993), a preocupação ambiental (Schultz, 2000; Stern et al., 1993), as atitudes (Kaiser, Wölfing, \& Fühner, 1999; Stern et al., 1995; Thompson \& Barton, 1994) e os estilos de vida (Corraliza \& Berenguer, 2000; Corraliza \& Martín, 2000; Degenhardt, 2002). Também figuraram na literatura como precursoras, as variáveis sociodemográficas (Stern et al., 1995) e as contextuais (De Young, 2000), embora sem uma tendência clara de sua influência sobre estas condutas. Além dessas, também se menciona o efeito das variáveis precursoras nos comportamentos, ressaltando a questão cultural e o impacto econômico, institucional, político e social da execução destes (Corral-Verdugo \& Pinheiro, 2004). Estes autores ainda defendem que a adoção de algumas condutas poderia afetar o mercado de trabalho - por exemplo, a redução extrema do consumo (um tipo de comportamento pró-ambiental); neste caso, nos países em vias de desenvolvimento, os principais afetados por esta redução poderiam ser os catadores de lixo ou as empresas que trabalham com resíduos, o que iria gerar outras preocupações, refletindo o impacto social desta preocupação ambiental.

Segundo Stern et al. (1995), partindo de um modelo causal, o Novo Paradigma Ambiental (Van Liere \& Dunlap, 
1978, 1981) estaria situado junto às crenças gerais, entre os valores e as crenças específicas, sobretudo, as que estão vinculadas a temas ambientais específicos, como, por exemplo, a reciclagem do lixo ou o uso racional da água. Assumindo a Teoria da Norma Altruísta de Schwartz (1977) como base, estes autores propõem a existência de possíveis crenças nas consequências dos seus comportamentos pró-ambientais, assim como daquelas responsáveis de evitar os danos ao meio ambiente e economizar recursos. Na discussão teórica sobre a preocupação dos efeitos negativos das ações do homem sobre o meio ambiente, a definição do Novo Paradigma Ambiental respondeu, em seu momento, a uma demanda, além de tornar-se um marco conceitual, na concepção de pesquisa sobre a relação do homem com a natureza sob o ponto de vista das crenças ambientais. Hernández e Hidalgo (2000) consideram o Novo Paradigma Ambiental (Van Liere \& Dunlap, 1978) como uma proposta para compreender os comportamentos pró-ambientais indo além do paradigma puramente ambientalista, que estes autores consideravam insuficiente. Assim, o modelo se define como uma série de ideias conjuntas que supõem uma visão de mundo contrária ao paradigma social antiecológico, o chamado Paradigma Social Dominante (PSD).

O PSD, como mencionam Dunlap (2008) e Dunlap et al. (2000), está relacionado ao sistema de crenças aceito e vigente nas sociedades ocidentais dos anos 1970. Neste modelo, o ser humano é independente da natureza e a sua função é dominála. Nesta concepção antropocêntrica, a preservação do meio ambiente estaria a serviço do homem e de suas necessidades. Por outro lado, o Novo Paradigma Ecológico (NEP) sugere uma proposta alternativa em que o princípio básico reside na condição em que os seres humanos formam parte do mundo natural e estão sujeitos às regras que ditam a natureza, entre elas, a interdependência das espécies. Assim, na visão ecocêntrica, diferente da antropocêntrica, a natureza possui um valor intrínseco e sua conservação é obrigatória, integrando aspectos de sustentabilidade no uso dos recursos. Entretanto, este modelo parece desconsiderar certos aspectos egoístas da cultura ecocêntrica. A interdependência das espécies e a proteção da natureza respondem às necessidades de sobrevivência do homem, que por sua vez protege, preserva e economiza recursos pensando no seu bem-estar no mundo.

Em sua revisão, Dunlap (2008) tentou lidar com as fraquezas do modelo da escala NEP original, dando continuidade ao enfoque ecológico e discutindo aspectos referentes à visão de mundo ecológica, além de trabalhar a relação entre os adventos da sociedade industrial, as preocupações ambientais e as crises ecológicas. Esta revisão significou avanços, uma vez que se adaptou a temas mais atuais, sem deixar de mencionar a preocupação com o meio ambiente, os valores ambientais e as crenças ambientais. Do mesmo modo que ocorreu com as versões anteriores, a escala foi criticada por alguns autores: Lalonde e Jackson (2002) e o próprio Dunlap (2008) a avaliaram como simplista; Chatterjee (2008) a considerou pouco aplicável a países subdesenvolvidos; Scott e Willits (1994) evidenciaram seu baixo potencial preditor de comportamentos pró-ambientais (crítica que não é recente nem unânime, indo ao encontro dos achados apresentados neste artigo). Ao mesmo tempo, outros estudos (Casey \& Scott, 2006; Olli, Grenstad, \& Wolleback, 2001) demonstram o contrário, valorizando a iniciativa de elaboração do instrumento. De todo modo, Dunlap (2008) esclarece que ao desenvolver esta escala não havia intenção de tratá-la como um instrumento preditor de comportamentos.

Tratando da possível dicotomia entre as crenças antropocêntricas e ecocêntricas, Thompson e Barton (1994) comprovaram empiricamente que um sujeito com crenças antropocêntricas também pode demonstrar preocupação com o meio ambiente, pensando nos benefícios materiais que isso pode lhe proporcionar, caracterizando o aspecto egoístico da conduta pró-ambiental. Mesmo que pareça contraditório, essas autoras demonstraram que ambas as posturas podem coexistir no mesmo sujeito, desconstruindo, de certa forma, o que propõe a NEP. De qualquer forma, este modelo se constituiu em uma referência relevante na literatura de crenças ambientais e consequentemente na pesquisa em Psicologia Ambiental. Detectar a estrutura das crenças ambientais individuais, neste caso em trabalhadores, serve de apoio para promover comportamentos favoráveis, assim como a conservação do meio ambiente por meio de hábitos mais respeitosos do homem para com este (Hernández \& Hidalgo, 2000). Por sua vez, Suárez (2000) reitera que as intervenções humanas na natureza podem gerar problemas ambientais, determinados por comportamentos diversos, tanto positivos como negativos.

Portanto, considerando a relevância desta temática tanto no contexto brasileiro como internacional, buscou-se testar algumas ideias. Em primeiro lugar, partiu-se da hipótese de que existiam diferenças nas crenças ambientais dos trabalhadores, sendo que os de empresa certificada, por estarem habituados aos SGA, apresentariam mais frequentemente crenças ambientais ecocêntricas. Em um segundo momento, buscou-se verificar se os trabalhadores dos outros dois grupos considerados (empresas não certificadas e não certificadas com política ambiental) demonstravam mais frequentemente crenças do tipo antropocêntricas, entendendo que isso aconteceria justamente devido a sua pouca conexão com temas ambientais no âmbito organizacional, acarretando em pouca identificação com a postura ecocêntrica.

Buscou-se, assim, discutir o poder preditor das crenças ambientais sobre os fatores de comportamentos pró-ambientais, pelo que realizou-se outras duas análises: uma a fim de verificar se as crenças ambientais ecocêntricas incidiam positivamente nas dimensões de comportamento pró-ambiental, e a outra para verificar se as crenças antropocêntricas estavam associadas à baixa incidência nas dimensões de comportamento próambientais.

\section{Método}

\section{Amostra}

Participaram da pesquisa 554 trabalhadores brasileiros, provenientes de 11 empresas privadas vinculadas ao setor industrial, que foram subdivididos em três grupos distintos $a$ priori, em função da empresa da qual procediam: certificadas, não certificadas e não certificadas, mas com política ambiental (Tabela 1). Destacam-se como características sociodemográficas 
dos participantes: ser do sexo masculino (73\%), ter até 10 anos de tempo de serviço no emprego atual (77\%), possuir pelo menos o ensino médio (78\%) e estar na faixa etária de 20 a 30 anos (50\%). Além disso, 21\% dos participantes ocupavam cargos de gestão.

\section{Instrumentos}

Para contrastar as hipóteses, utilizou-se dois instrumentos: a Escala de Crenças Ambientais (ECA) e a Escala de Comportamentos Ecológicos (ECE). A ECA foi elaborada e

Tabela 1

Distribuição da amostra

\begin{tabular}{llcc}
\hline \multicolumn{1}{c}{ Grupos } & \multicolumn{1}{c}{ Características } & $N$ & $\%$ \\
\hline Grupo I & Procedentes de empresa certificada & 232 & 41,9 \\
Grupo II & Procedentes de empresa não certificada & 153 & 27,6 \\
Grupo III & Procedentes de empresa não certificada com política ambiental & 169 & 30,5 \\
\hline Total & & 554 & 100 \\
\hline
\end{tabular}

validada para a população brasileira por Pato (2004). Ela possui 26 itens sobre temas ambientais relacionados com características naturais e problemas ambientais (do Brasil e globais) e sobre a relação do homem com o meio ambiente, avaliando o grau de concordância numa escala Likert de cinco pontos $(1=$ discordo totalmente e 5 = concordo totalmente). Como exemplo, na dimensão ecocêntrica: "Separar o lixo conforme o tipo ajuda na preservação do meio ambiente"; na dimensão antropocêntrica: “O Brasil é um país com muitas riquezas naturais e é impossível que essas riquezas acabem apenas pelas ações humanas". A análise de confiabilidade para esta amostra demonstrou um bom índice de consistência interna, sendo na dimensão de crenças antropocêntricas (10 itens; $\alpha=0,691)$ e na de crenças ecocêntricas ( 16 itens; $\alpha=0,738$ ). Esta escala foi utilizada por ser capaz de identificar a estrutura do sistema de crenças ambientais de brasileiros e cumprir um dos objetivos deste estudo que é verificar as diferenças entre a dicotomia das crenças ambientais ecocêntricas versus antropocêntricas de trabalhadores fora do ambiente de trabalho.

A ECE foi criada e validada no Brasil por Pato (2004) visando medir comportamentos ecológicos a partir da percepção dos sujeitos. Ela foi inspirada nas escalas de Kaiser (1998) e Karp (1996), e propõe 29 itens para medir a frequência de comportamentos ecológicos específicos. Para tanto é usada uma escala Likert de seis pontos (na qual "1" significa nunca, e "6", sempre), dividida em quatro fatores e cinco itens de desejabilidade social. Foi realizada a análise de confiabilidade para cada fator em nossa amostra (apresentada junto à descrição de cada fator):

Economia de água e luz. É composto por 12 itens $(\alpha=$ 0,770 ) e diz respeito àqueles comportamentos de não desperdiçar energia e água, como por exemplo "Quando estou em casa, deixo as luzes acesas em ambientes que não são usados”.

Limpeza. Este fator $(\alpha=0,694)$ refere-se aos cinco itens associados à manutenção do ambiente limpo ("Quando não encontro lixeira por perto, jogo latas vazias no chão").

Ativismo/consumo. Agrupa nove itens $(\alpha=0,763)$ relacionados à preservação e à conservação do meio ambiente, por meio de participação ativa que envolva outras pessoas, ou por meio de decisão de compra e de uso de produtos considerados nocivos ou não ao meio ambiente, e mobilização ("Participo de manifestações públicas para defender o meio ambiente",
"Compro comida sem me preocupar se têm conservantes ou agrotóxicos").

Reciclagem. Reúne três itens $(\alpha=0,262)$ sobre ações de separação de resíduos domésticos conforme o tipo ("Providenciei uma lixeira específica para cada tipo de lixo em minha casa").

A escala também disponibiliza cinco itens de desejabilidade social $(\alpha=0,521)$ descrevendo comportamentos ecológicos pouco frequentes ("Entrego as pilhas usadas nos postos de coleta"). A escala foi utilizada tal como propõe a versão apresentada pela autora, incluindo os quatros fatores de comportamento pró-ambiental nas análises. Por tratar-se de uma amostra de trabalhadores e o foco desta pesquisa estar nos seus comportamentos ecológicos fora da empresa, não se realizou adaptação da escala para o âmbito organizacional.

Com o intuito descritivo, foram coletados alguns dados sociodemográficos da amostra, tais como sexo, idade, cargo, tempo de atuação na empresa e nível de estudos.

\section{Procedimentos}

Para alcançar os objetivos propostos, foram contatadas empresas brasileiras do setor industrial privado, quando se esclareceu os objetivos da pesquisa ao responsável pelo setor de meio ambiente de cada empresa, que atuou posteriormente como intermediário entre os trabalhadores e os pesquisadores. A utilização de web survey nas pesquisas em empresas é defendida por Rhodes, Bowie, e Hergenrather (2003), autores que também recomendam a combinação de métodos, pois em situações nas quais há somente a utilização da versão online a amostra se restringe ao perfil usuário de internet. Assim, com o intuito de atingir o maior número de respondentes dentro das organizações, foram disponibilizadas duas versões dos mesmos instrumentos - papel e online - sendo solicitado que cada trabalhador optasse por uma das modalidades. Dos 600 questionários distribuídos em versão de papel, obtivemos um índice de resposta de $61,3 \%$ ( $n$ $=368) ; 168$ trabalhadores $(33,6 \%)$ optaram pela versão online. Entre as respostas obtidas da versão papel, a porcentagem mais elevada de respostas perdidas não ultrapassou 3\%, ao passo que na versão online os questionários foram preenchidos na sua totalidade seguindo as tendências descritas em pesquisas (Descombe, 2006). A coleta de dados ocorreu entre os meses de janeiro e abril de 2008 .

Para verificar as diferenças existentes entre as crenças ambientais nos três grupos de trabalhadores, aplicou-se a análise 
de variância, utilizando-se a ANOVA com a prova de contraste $a$ posteriori de Scheffé. Logo, para comprovar o poder preditivo das dimensões das crenças ambientais sobre o comportamento pró-ambiental, utilizou-se a Regressão Linear Múltipla, pela qual os quatro fatores de comportamento pró-ambiental atuaram como variáveis dependentes e as dimensões das crenças ambientais como variáveis independentes. Foi realizada análise adicional de correlação entre os cinco itens de desejabilidade social, excluídos da análise de regressão, e os fatores de comportamento pró-ambiental.

\section{Resultados}

A Tabela 2 destaca as crenças ambientais quanto às suas médias e desvios padrão, nos três grupos. Destes resultados, pode-se certificar que as diferenças entre as médias das crenças ambientais nos três grupos é estatisticamente pequena, o que se comprovou com a análise da variância. A ANOVA validou a constatação que não havia diferenças estatisticamente significativas quanto às médias das crenças ecocêntricas $(F=$ $0,569 ; p=0,566)$ no Grupo I em relação aos demais. Por outro lado, os outros dois grupos (Grupo II e Grupo III) possuem pontuações mais altas nas crenças antropocêntricas. Por meio da ANOVA e do Teste Scheffé da Tabela 3 se verificam diferenças significativas entre o Grupo I e os Grupos II e III.

Para verificar o quanto as crenças ecocêntricas atuavam como precursoras dos fatores de comportamento pró-ambiental em toda a amostra, realizou-se uma análise de regressão multivariada padrão por fator. Pode-se comprovar que tanto as crenças ecocêntricas como as antropocêntricas se associam positivamente à dimensão de comportamento ativismo e consumo (Tabela 4). Em relação ao fator reciclagem, existe relação inversa das crenças antropocêntricas com estes comportamentos, ou seja, os trabalhadores que possuem este tipo de crença manifestam menos este tipo de comportamento.

Quanto ao fator economia de água em luz, as crenças

Tabela 2

Médias das dimensões das escalas ECA nos três grupos

\begin{tabular}{lcccccc}
\hline \multirow{2}{*}{ Crenças } & \multicolumn{2}{c}{ Grupo I } & \multicolumn{2}{c}{ Grupo II } & \multicolumn{2}{c}{ Grupo III } \\
& $M$ & $D P$ & $M$ & $D P$ & $M$ & $D P$ \\
\hline Crenças antropocêntricas & 2,38 & 0,67 & 2,58 & 0,70 & 2,68 & 0,68 \\
Crenças ecocêntricas & 4,38 & 0,39 & 4,35 & 0,43 & 4,34 & 0,45 \\
\hline Nota. A diferença das médias é significativa ao nível 0,05 & \multicolumn{4}{c}{}
\end{tabular}

ecocêntricas aparecem como preditoras positivas destas ações $(\beta$ $=0,19 ; p=0,00)$. Considerando coeficiente de determinação $\left(R^{2}\right.$ $=0,039 ; R^{2}$ ajustado $=0,036$ ), estes resultados levam a considerar que o sujeito que manifestar estas crenças em relação ao meio ambiente estaria mais disposto a realizar ações cotidianas considerando a economia de recursos. Finalmente, referente ao fator limpeza, detectou-se que as crenças ecocêntricas atuam como preditoras positivas destas ações $(\beta=0,18 ; p=0,00)$, ao

Tabela 3

Teste de Scheffé (crenças antropocêntricas como variável dependente) nos três grupos

\begin{tabular}{llccc}
\hline (I) Tipo Empresa & (J) Tipo Empresa & Diferença de médias (I-J) & Erro típico & $p$ \\
\hline \multirow{2}{*}{ Grupo I } & Grupo II & $-0,20$ & 0,07 & 0,01 \\
& Grupo III & $-0,30$ & 0,06 & 0,00 \\
\multirow{3}{*}{ Grupo II } & Grupo I & 0,20 & 0,07 & 0,01 \\
& Grupo III & $-0,10$ & 0,07 & 0,42 \\
\multirow{2}{*}{ Grupo III } & Grupo I & 0,30 & 0,06 & 0,00 \\
& Grupo II & 0,10 & 0,07 & 0,42 \\
\hline
\end{tabular}

Nota. A diferença das médias é significativa ao nível 0,05 .

passo que as antropocêntricas demonstram relação inversa $(\beta=$ $-0,24 ; p=0,00)$.

Para discutir o quanto os itens de desejabilidade social influenciaram os trabalhadores a responder o questionário, realizamos a análise de correlação destes itens com os fatores de comportamento. Esta nos indicou que há correlações significativas entre os itens de desejabilidade social e os comportamentos (Tabela 5), o que significa que essa amostra pode ter sido influenciada pela desejabilidade social ao responder os questionários.

Tabela 4

Coeficientes de regressão ( $\mathrm{B}$ e $\beta$ ) e $\mathrm{R}, \mathrm{R}^{2}$ e $\mathrm{R}^{2}$ ajustado para da regressão padrão entre as crenças ambientais e os fatores de comportamento ativismo/consumo e reciclagem

\begin{tabular}{llcccccc}
\hline Variável Dependente & Variável Independente & $\mathrm{B}$ & $\beta$ & $P$ & $R$ & $R^{2}$ & $R^{2}$ ajustado \\
\hline \multirow{2}{*}{ Ativismo/Consumo } & Crenças antropocêntricas & 0,11 & 0,08 & 0,04 & \multirow{2}{*}{0,125} & \multirow{2}{*}{0,016} & \multirow{2}{*}{0,012} \\
& Crenças ecocêntricas & 0,22 & 0,10 & 0,01 & & & \multirow{2}{*}{0,025} \\
\multirow{2}{*}{ Reciclagem } & Crenças antropocêntricas & $-0,26$ & $-0,14$ & 0,00 & \multirow{2}{*}{0,168} & 0,028 & \multirow{2}{*}{0,025} \\
& Crenças ecocêntricas & 0,23 & 0,07 & 0,07 & & \\
\hline
\end{tabular}


Tabela 5

Coeficiente de correlação de Pearson entre os itens de desejabilidade social e os fatores de comportamento pró-ambiental $(N=554)$

\begin{tabular}{|c|c|c|c|c|c|c|c|c|c|}
\hline Item/Fator & 1 & 2 & 3 & 4 & 5 & 6 & 7 & 8 & 9 \\
\hline $\begin{array}{l}1 \text { Dou todo o dinheiro que posso para } \\
\text { uma ONG ambientalista }\end{array}$ & - & & & & & & & & \\
\hline 2 Entrego papéis para reciclagem & 0,08 & - & & & & & & & \\
\hline $\begin{array}{l}3 \text { Quando vejo alguém jogando papel } \\
\text { na rua, pego e jogo na lixeira }\end{array}$ & 0,06 & 0,24 & - & & & & & & \\
\hline 4 Evito alimentos transgênicos & $.0,03$ & 0,16 & 0,21 & - & & & & & \\
\hline $\begin{array}{l}5 \text { Entrego as pilhas usadas nos postos } \\
\text { de coleta }\end{array}$ & $-0,01$ & 0,30 & 0,31 & 0,23 & - & & & & \\
\hline 6 Reciclagem & $-0,03$ & 0,33 & 0,15 & 0,10 & 0,19 & - & & & \\
\hline 7 Economia & $-0,10$ & 0,19 & 0,15 & 0,14 & 0,12 & 0,23 & - & & \\
\hline 8 Limpeza & $-0,26$ & 0,19 & 0,23 & 0,07 & 0,23 & 0,32 & 0,44 & - & \\
\hline 9 Ativismo/Consumo & 0,15 & 0,33 & 0,52 & 0,41 & 0,40 & 0,20 & 0,20 & 0,26 & - \\
\hline
\end{tabular}

Nota. Todas as correlações foram significativamente diferentes de zero $(p<0,001)$

\section{Discussão}

Pode-se demonstrar na literatura a presença do debate sobre a explicação dos comportamentos pró-ambientais por meio da dicotomia das crenças ambientais ecocêntricas versus antropocêntricas. Corral-Verdugo (2001) defende que, mesmo que o sujeito possua crenças ambientais ecocêntricas ou de integração com a natureza, o seu comportamento pode ser contrário a essa tendência, movido pela dificuldade de exercer tal ação. Neste caso, se aplicariam as condutas de reciclagem de resíduos, já que essas demandam maior investimento temporal do sujeito. O presente estudo, em que se buscou comprovar a relação entre as crenças ambientais e os comportamentos pró-ambientais nos trabalhadores do Grupo I, não confirmou esta hipótese a priori. Entretanto, nas provas de contraste, foi possível verificar que existem diferenças nas crenças ambientais do Grupo I em relação aos Grupos II e III. Isto poderia significar uma maior manifestação de crenças ecocêntricas por parte do Grupo I em relação aos demais trabalhadores, que poderia refletir nos comportamentos pró-ambientais. Seguindo a linha de Corral-Verdugo e Zaragoza (2000), o conhecimento prévio sobre temas ambientais do Grupo I como resultado do SGA e as crenças podem, então, se caracterizar como preditores de alguns destes comportamentos. Da mesma forma, podemos contextualizar as considerações levantadas por García-Mira et al. (1998) em relação aos resultados do Grupo I. Estes autores questionaram a pressão social dos colegas de trabalho como possíveis impulsores de condutas ambientais responsáveis, dando ênfase ao papel relevante dos treinamentos ambientais nas empresas. Esta poderia ser uma das justificativas a manifestação mais significativa das crenças ecocêntricas neste grupo, podendo estar associado à realização de comportamentos pró-ambientais condizentes fora da empresa.

O fato de estar habituado a uma cultura ambiental, facilitada pelo SGA das empresas, foi relevante no momento de diferenciar as crenças ambientais dos trabalhadores desta amostra, embora não se tenha confirmado seu poder preditivo sobre todos os fatores de comportamento pró-ambiental. Desta forma, se questiona o quanto e como a empresa se preocupou em transmitir ou mudar os valores ambientais pessoais de seus colaboradores ao momento de implantar estes sistemas, fato que não foi possível controlar neste estudo. Fussler e James (1998) defendem que mesmo que a mudança ambiental experimentada pela organização não seja radical, o SGA modifica alguns aspectos organizacionais, entre eles, como foi possível observar neste trabalho, alguns fatores do comportamento pró-ambiental, como os de economia e limpeza fora da empresa.

Pode-se confirmar a relação positiva das crenças ecocêntricas com o comportamento pró-ambiental de economia e ativismo/ consumo. Entretanto, especialmente o fator de ativismo/ consumo pode ser contextualizado na leitura de Thompson e Barton (1994), de que estas ações podem denotar posturas egoístas, no sentido que o sujeito as realiza pensando em seu benefício próprio. Da mesma forma, pode-se inferir que os comportamentos de economia estão bastante vinculados ao orçamento, podendo sofrer influências não consideradas neste estudo, como por exemplo, os efeitos financeiros da economia de recursos no balanço financeiro doméstico ou organizacional. Corral-Verdugo e Pinheiro (2004) questionam o impacto social de alguns comportamentos, entre estes, no contexto desta discussão, questionamos o quanto economizar recursos, mesmo do ponto de vista egoísta, pode repercutir na esfera doméstica. Em relação ao fator reciclagem, em que houve relação inversa com as crenças antropocêntricas, faz sentido mencionar que aqueles que acreditam que o meio ambiente está a sua disposição e que há independência entre ambos, a ação de reciclar parece estar desconectada ao viés egoístico, realizando este com menos incidência. Isto pode ser explicado nas inconsistências teóricas descritas por Dunlap (2008), referentes à fraqueza de seu modelo ao predizer comportamentos discutindo com mais ênfase a visão de mundo ecológica utópica distante da realidade organizacional.

A análise de correlação dos itens de desejabilidade social com os fatores de comportamentos sugeriu que os trabalhadores sofreram influência destes no momento de responder as questões. Resultado que leva a refletir sobre a declaração dos participantes de executar certos comportamentos pouco frequentes na população, como entregar as pilhas ao posto de coleta, ser 
influenciado por outras variáveis que não foram consideradas como as contextuais (De Young, 2000).

\section{Considerações Finais}

O comportamento pró-ambiental pode ser explicado por diversos aspectos, tanto individuais (crenças ambientais) como organizacionais (por meio do SGA, por exemplo). A literatura demonstrou a amplitude de variáveis passíveis de predizer estes comportamentos assim como as dificuldades de detectá-las. Este estudo buscou avaliar as diferenças nas crenças ambientais numa amostra de trabalhadores - parte deles habituados ao SGA e parte não habituados, comprovando os efeitos da familiaridade com estes sistemas nos comportamentos pró-ambientais fora da empresa.

Por haver trabalhado com condutas ambientais na esfera doméstica, foi pedido aos trabalhadores, mediante escalas, reflexões sobre sua rotina ambiental fora do ambiente organizacional. Desta forma, como crítica, esta pesquisa se limitou, logicamente, aos aspectos tratados pelas perguntas presentes nestes questionários. Isto se reitera quando se detecta a influência da desejabilidade social ao responder às questões, podendo estar relacionada às condições de aplicação do questionário ou mesmo à realização deste tipo de pesquisa no contexto organizacional. Compartilhamos das ideias de alguns autores (Corral-Verdugo \& Pinheiro, 2004; Pato \& Tamayo, 2006) que pontuam que trabalhar com condutas pró-ambientais é estar condicionado aos questionários de autorrelato, já que alguns comportamentos ocorrem na vida privada do sujeito e se faz necessário respeitar sua individualidade. Desta forma, mesmo reconhecendo estas limitações, para estudos futuros é sugerido o desenvolvimento de alternativas para buscar controlar estes efeitos.

A proposta de comprovar as diferenças entre as crenças ambientais em trabalhadores de diferentes tipos de empresa, assim como identificar variáveis que explicam os comportamentos pró-ambientais, vem ao encontro de uma lacuna na literatura. Os estudos que trabalharam com estas variáveis o fizeram considerando o ponto de vista individual. Trabalhar com o coletivo de trabalhadores, principalmente os provenientes de empresas certificadas pelos SGA, traz consigo um desafio: o de identificar o potencial educativo cidadão que as organizações têm em suas mãos. Portanto, é preciso ressaltar que estes resultados servem de indicação aos responsáveis da área de recursos humanos, assim como aos educadores e gerentes que têm a responsabilidade de sensibilizar este coletivo às questões ambientais dentro das empresas, resultando em ações com reflexo na esfera doméstica.

Do ponto de vista acadêmico e da pesquisa, este estudo traz resultados que contemplam um número restrito de variáveis, justificado pelo modelo empírico que aqui se descreve. Entretanto, fica evidente que esta aproximação traz consigo dados relevantes para que haja continuidade na pesquisa com comportamentos pró-ambientais neste tipo de amostra e contexto (trabalhadores, organizações e Sistemas de Gestão Ambiental), possibilitando o desenvolvimento de escalas mais específicas para este universo.

\section{Referências}

Alberton, A., \& Costa Jr., N. C. A. (2007). Meio ambiente e desempenho econômico-financeiro: benefícios dos Sistemas de Gestão Ambiental (SGAs) e o impacto da ISO 14001 nas empresas brasileiras. RAC-Eletrônica, 1, 153-171.

Amérigo, M., \& González, A. (2001). Los valores y las creencias medioambientales en relación con las decisiones sobre dilemas ecológicos. Estudios de Psicología, 22(1), 65-73.

Casey, P. J., \& Scott, K. (2006). Environmental concern and behavior in an Australian sample within an econcentric-anthopocentric framework. Australian Journal of Psychology, 58, 57-67.

Chatterjee, D. P. (2008). Oriental disadvantage versus oriental exuberance: appraising environmental concern in India. International Sociology, 23, 5-33.

Corraliza, J. A., \& Berenguer, J. (2000). Environmental values, beliefs, and actions. A situational approach. Environment and Behavior, 32(6), 832-848.

Corraliza, J. A., \& Martín, R. (2000). Estilos de vida, actitudes y comportamientos ambientales. Medio Ambiente y Comportamiento Humano, 1(1), 31-56.

Corral-Verdugo, V. (2001). Comportamiento proambiental: una introducción al estudio de las conductas protectoras del ambiente. Santa Cruz de Tenerife, Espanha: Resma.

Corral-Verdugo, V., \& Pinheiro, J. Q. (1999). Condições para o estudo do comportamento pró-ambiental. Estudos de Psicologia (Natal), 4, 7-22.

Corral-Verdugo, V., \& Pinheiro, J. Q. (2004). Aproximaciones al estudio de la conducta sustentable. Medio Ambiente y Comportamiento Humano, 5, 1-26.

Corral-Verdugo, V., \& Zaragoza, F. (2000). Bases sociodemográficas y psicológicas de la conducta de reutilización: un modelo estructural. Medio Ambiente y Comportamiento Humano, 1(1), 9-29.

Degenhardt, L. (2002). Sustainable lifestyle pioneers. In P. Schmuck \& W Schultz (Orgs.), Psychology of Sustainable Development (pp. 123-147). Boston: Kluwer Academic.

Descombe, M. (2006). Web-based questionnaires and the mode effect: an evaluation based on completion rates and data Contents of near-identical questionnaires delivered in different modes. Social Science Computer Review, 24, 246-254.

De Young, R. (2000). New ways to promote proenvironmental behavior: expanding and evaluating motives for environmentally responsible behavior. Journal of Social Issues, 56, 509-526.

Dunlap, R. E. (2008). The New Environmental Paradigm Scale: from marginality to worldwide use. Journal of Environmental Education, 40(1), 19-28.

Dunlap, R. E., Van Liere, K. D., Mertig, A. G., \& Jones, R. E. (2000). Measuring endorsement of the New Ecological Paradigm: a revised NEP Scale. Journal of Social Issues, 56, 425-442.

Fussler, C., \& James, P. (1998). Eco-innovación: integrando el medio ambiente en la empresa del futuro. Madrid: Mundi-Prensa.

García-Mira, R., Santos, M. C., Gómez-Duran, B., Romay, J., \& Fernández, M. A. (1998). Evaluación de las actitudes pro ambientales en trabajadores de grandes organizaciones. Revista de Psicología Social, 13, 435-444.

Grob, A. (1995). A structural model of environmental attitudes and behavior. Journal of Environmental Psychology, 15, 209-220.

Hernández, B., \& Hidalgo, M. C. (2000). Actitudes y creencias hacia el medio ambiente. In J. I. Aragonés \& M. Amérigo (Orgs.), Psicología Ambiental (pp. 309-330). Madrid: Pirámide.

Hillary, R. (2000). ISO 14001: case studies and practical experiences. Wiltshire: Greenleaf Publishing.

Instituto Nacional de Metrologia, Normalização e Qualidade Industrial. (2008). Certificação ISO 14000 no Brasil. Recuperado de http://www.inmetro.gov. $\mathrm{br} / \mathrm{gesta0} 14001$

Intergovernmental Panel on Climate Change. (2007). Cambio climático 2007: informe de sintesis. Recuperado de http://www.ipcc.ch

Kaiser, F. G. (1998). A general measurement of ecological behavior. Journal of 
Applied Social Psychology, 28, 395-422.

Kaiser, F. G., Wölfing, S., \& Führer, U. (1999). Environmental attitude and ecological behavior. Journal of Environmental Psychology, 19, 1-19.

Karp, D. G. (1996). Values and their effect on pro-environmental behavior. Environment and Behavior, 28(1), 111-133.

Lalonde, L., \& Jackson. E. L. (2002). The New Environmental Paradigm Scale: how it outlived its usefulness? Journal of Environmental Education, 33(4), 28-36.

Olli, E., Grendstad, G., \& Wolleback, D. (2001) Correlates of environmental behaviors: bringing back social context. Environment and Behavior, 33, $181-208$

Pato, C. M. L. (2004). Comportamento ecológico: relações com valores pessoais e crenças ambientais. (Tese de Doutorado, Universidade de Brasília, Brasília).

Pato, C. M. L., \& Tamayo, A. (2006). A Escala de Comportamento Ecológico: desenvolvimento e validação de um instrumento de medida. Estudos de Psicologia (Natal), 11, 289-296.

Rhodes, S. D., Bowie, D. A., \& Hergenrather, K. C. (2003). Collecting behavioral data using the World-Wide Web: considerations for researchers. Journal and Community Health, 57, 68-73.

Schultz, W. (2000). Empathizing with nature: the effects of perspective taking on concern for environmental issues. Journal of Social Issues, 56, 391-406.
Schwartz, S. H. (1977). Normative influences on altruism. In L.Berkowitz (Org.), Advances in experimental social psychology (pp. 221-279). London: Academic Press.

Scott, D., \& Willits, F. K. (1994). Environmental attitudes and behavior: a Pennsylvania Survey. Environment and Behavior, 26, 239-260.

Stern, P. C., Dietz, T., \& Kalof, L. (1993). Value orientations, gender, and environmental concern. Environment and Behavior, 25, 322-348.

Stern, P. C., Dietz, T., Kalof, L., \& Guagnamo, G. A. (1995). Values, beliefs, and proenvironmental action: attitude formation toward emergent attitude objects. Journal of Applied Social Psychology, 25(18), 1611-1636.

Suárez, E. (2000). Problemas ambientales y soluciones conductuales. In J. I. Aragonés \& M. Amérigo (Orgs.), Psicología Ambiental (pp. 331-355). Madrid: Pirámide.

Thompson, S. C., \& Barton, M. (1994). Ecocentric and anthropocentric attitudes toward the environment. Journal of Environmental Psychology, 14, 149-157.

Tinsley, S., \& Pillai, I. (2006). Environmental management systems: understanding organizational drivers and barriers. London: Earthscan.

Van Liere, K. D., \& Dunlap, R. E. (1978). The New Environmental Paradigm. Journal of Environmental Education, 9, 10-19.

Van Liere, K. D., \& Dunlap, R. E. (1981). Environmental concern: does it make a difference how it's measured? Environment and Behavior, 13, 651-676.

Camila Bolzan de Campos, doutora em Psicologia Social pela Universidade de Barcelona (UB), é coordenadora de pós-graduação, extensão e pesquisa da Faculdade de Tecnologia Tecbrasil (FTEC BRASIL). Endereço para correspondência: Avenida São Paulo, 243/403. Bento Gonçalves-RS. CEP: 95700-000. Telefone: (54) 3702-4585. E-mail: camilabcampos@msn.com

Enric Pol, doutor catedrático de Psicologia Social e Ambiental pela Universidade de Barcelona (UB), é diretor do Departamento de Psicologia Social da mesma instituição. E-mail: epol@ub.edu 